\title{
Analysis of Industrial Agglomeration in Shaanxi Province Based on Location Quotient Theory
}

\author{
Zhang xinli $^{1 a^{*}} \quad$ Wang qin ${ }^{1 b}$ \\ ${ }^{1}$ School of Economics and Management of Xi'an Technological University \\ Xi'an Shaanxi China \\ a905769469@qq.com, b1208530049@qq.com \\ "Zhang xinli
}

Key words : industrial agglomeration; evaluating the industrial agglomeration; location quotient

\begin{abstract}
Industrial agglomeration has become an important way of regional economic development in the world. More and more researches are devoted to evaluating the level of industrial agglomeration. This paper analyzes the agglomeration level of Shaanxi Province industry with location quotient index from the perspective of industrial output, number of enterprises, and employees. Studies show that the degree of agglomeration of the primary industry in Shaanxi Province is relatively low. The second and third industries have relatively high degree of agglomeration and have comparative advantages. Finally, the paper proposes countermeasures for how to promote the development of Shaanxi's industry.
\end{abstract}

\section{基于区位熵理论的陕西省产业集聚分析}

\author{
张新丽 $^{1 \mathrm{a} *}$ ，王芹 ${ }^{1 \mathrm{~b}}$ \\ 1西安工业大学经济管理学院, 西安, 陕西, 中国 \\ a905769469@qq.com, b1208530049@qq.com \\ *张新丽
}

关键词：产业集聚 产业集聚测度 区位摘

摘 要: 产业集聚己成为世界范围内区域经济发展的重要方式, 越来越多的研究致力于对产业 集聚水平测度的探索。本文采用区位熵指数从工业产值、企业数、从业人员等方面对陕西省 产业进行集聚水平分析, 研究表明陕西省第一产业集聚度较低, 第二、三产业集聚度较高, 具有相对优势。最后针对如何促进陕西省产业发展提出对策建议。

1. 引言

世界正发生着复杂而深刻的变化，为了应对世界经济多极化、经济全球化的影响，许多 国家根据本国的发展特点, 纷纷提出新的经济发展策略。为了适应世界经济变换的潮流, 我 
国提出了 “一带一路” 国家战略, 着力建立开放型世界经济, 积极推动经济的稳定发展。陕 西作为“一带一路”重要经济区, 是联系中亚、南亚、西亚国家的通道, 也是重要的商贸与物 流枢纽和人文交流基地。国家西部大开发战略布局中，陕西是欧亚大陆桥经济带的核心支撑 区, 具有带动西部区域经济快速增长的重要作用。如何加速陕西的经济发展, 研究陕西经济 产业集聚对西部区域经济发展及影响和带动作用，引起了政府和学术界的高度关注。

产业集聚是产业发展演化过程中的一种区域组织形式, 指一定数量企业在某个特定地理 区域内高度集中从而实现集聚效益的一种现象。产业集聚在经济增长中起着重要作用, 产业 集聚的发展是适应全球化及日益激烈的竞争新趋势, 是应对新的竞争压力行之有效的区域经 济发展模式，是现阶段产业竞争力的重要来源和集中表现。

国外对于产业集聚的研究起步较早, Mashall指出产业集聚能提供专业技能的劳动市场, 促进 更多的就业, 进而降低劳动力出现短缺的可能性, 同时由于集聚的溢出效应, 集群中的企业 更容易获得技术、信息等方面的优势 ${ }^{[1]}$ 。Krugman、Ellision研究表明在美国的制造业中存在

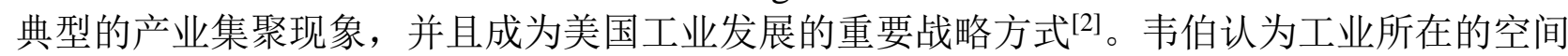
位主要取决于成本因素, 成本优势可吸引其他企业的进入 ${ }^{[3]}$ 。Storper等人认为集聚是工业增 长的一种基本空间结构模式 ${ }^{[4]}$ 。

国内对于产业集聚的研究始于上世纪 90 年代, 由于产业的地区集中现象日益普遍, 对经 济的推动作用越来越明显, 引起了国内学者的关注, 王子龙和谭清美等人对 1994-2003 连 续十年的部分中国制造产业集聚水平进行了测度 ${ }^{[5]}$ 。王缉慈认为产业集聚是众多同类企业及 相关机构等在地理上集聚形成该产业巨大竞争优势的现象 ${ }^{[6]}$ 。吴学花, 杨德馨等人测度了中 国 20 个二位数制造业行业的集聚水平，分析认为中国制造业已表现出较强的集聚性 ${ }^{[7]}$ 。刘 修研等利用全国规模以上工业企业数据, 发现地区产业专业化水平、市场潜能和地区要素禀 赋等对产业动态集聚有显著的正影响 ${ }^{[8]}$ 。唐杰利用 CES 形式函数对天津市进行了集聚效果分 析 ${ }^{[9]}$ 。

综上所述，针对产业集聚的研究中，研究产业集聚的性质及成因的较多，研究产业集聚 水平测度的相对较少; 从采用的研究方法来看, 以定性研究的居多, 而采用定量分析的相对 较少; 在研究区域上, 对全国、东部地区研究较多, 对西部地区研究较少。因此, 本文选择 陕西省作为研究对象, 利用区域商指数详细分析了陕西三次产业的集聚程度, 并提出相应的 发展对策, 对提高陕西产业的集聚度, 促进优势产业发展, 提高地区竞争力有一定的理论意 义与现实意义。

\section{2.产业集聚水平的测度方法的选取}

产业集聚水平的测度可以使用定性分析法和定量分析法。定性分析法主要有企业调研法、 专家意见法等。定性分析虽然可以判断企业是否存在集聚效应, 并进行相关的产业集聚分析。 但是定量分析可以更精准的反映出一个地区的产业集聚效应。衡量产业集聚度的指标有多种, 常用的测算方法有: 赫芬达尔指数、行业集中度、空间基尼系数、EG指数、空间集聚指数和 区位熵等指数。各个指标都有一定的适用范围, 适合不同的研究需要, 比如使用集中率和赫 芬达尔指数来衡量集聚水平, 一般是从产业组织的角度, 以产业内的各个企业为考察对象来 分析产业的市场集聚度。而本文既要从区域的角度去研究集聚度, 同时要从产业组织的角度 去考察陕西省产业的集聚状况。基于此考虑, 本文将选取区位熵指数来测度陕西省产业的集 聚水平。

经济学理论界常用的区位熵指数（Location Quotient, LQ）是通过测定某些产业在某地区 的相对专业化程度来间接反映区域间的产业结构和发展方向的一种测量产业集聚程度的计算 方法。区位熵指数在实际应用时, 可以选择就业人数、总产值、销售收入、企业数量、资产 总额等指标分别进行度量。因此, 通过计算某一区域产业的区位熵, 可以用来分析该区域优 势产业的状况, 并能找出该区域在全国具有一定地位的产业。区位熵具体计算公式如下: 


$$
L Q_{i j}=\frac{q_{i j} / \sum_{j=1}^{m} q_{i j}}{\sum_{i=1}^{n} q_{i j} / \sum_{i=1}^{n} \sum_{j=1}^{m} q_{i j}}
$$

其中, $i$ 表示第 $i$ 个产业, $j$ 表示第 $j$ 个地区; $q_{i j}$ 为 $j$ 地区的 $i$ 产业的相关指标 (例如产值、 就业人数、销售收入、企业数量等)。根据式 (1), 区位熵指数与该地区该产业的专业化程度 成正比, 区域熵指数越大表明该地区该产业的专业化程度越高, 集聚能力和集聚程度就越强。

通常 $\mathrm{LQ}_{\mathrm{ij}}>1$, 说明该地区该产业具有比较高的集聚度, 专业化程度超过全国平均水平, 有很 强的竞争优势, 可以适时的加大对外扩张的力度; $\mathrm{LQ}_{\mathrm{ij}}=1$, 表明该地区该产业专业化水平与 全国水平持平, 产业集聚现象不明显; $\mathrm{LQ}_{\mathrm{ij}}<1$, 表明该地区该产业集聚度较低, 没有形成明 显的集聚, 需要从区域外输入该行业, 以满足区域内生产与生活的需求。这种测算方法也有 一定的局限性, 区位熵指数的测算能够看出区域内的产业走向并判断该区域的产业是否形成 集聚, 但对于集聚区的规模、构成和产业间的相互关联性却无法指出。另外, 该方法注重静 态分析, 对产业融合不能更准确的了解。

\section{3.基于区位摘的陕西省经济集聚度分析}

\section{1 第一产业集聚度分析}

根据区位熵的相关分析与计算方法, 本文收集整理了《陕西省统计年鉴》2015-2017 年 的相关数据, 对陕西省近三年第一产业的经济数据进行产业集聚度分析, 结果如表 1 所示。

表 1 陕西省第一产业集聚度

\begin{tabular}{|c|c|c|c|c|}
\hline 年份 & 农业 & 林业 & 牧业 & 渔业 \\
\hline 2014 & 1.27 & 0.64 & 0.83 & 0.07 \\
\hline 2015 & 1.28 & 0.65 & 0.85 & 0.08 \\
\hline 2016 & 1.28 & 0.69 & 0.82 & 0.08 \\
\hline
\end{tabular}

从表 1 中可以看出, 陕西省的农业表现出较高的聚集水平, 区位熵值平均在 1.28 , 高于 全国平均水平，这也符合陕西省是农业大省的情况，而其他三个产业，林业、牧业和渔业就 不具备集聚优势, 特别是渔业最为明显, 区位摘指数不足 0.1 。从时间上看, 陕西省第一产业 内部连续三年没有太大变化, 各个行业的集聚水平基本保持稳定。

\section{2 第二产业集聚度分析}

按照我国行业分类的标准，《陕西省统计年鉴》2017 工业行业分类包含了三大门类。进 一步按照两位数大类分类来看, 采矿业、制造业、电热燃水生产供应业共计 40 个大类。资 料表明大多数实证分析中人们分析行业区位摘会从产业总产值、企业数量、产业销售收入、 产业从业人员、产业增加值等指标中选择其一进行计算, 但是, 不同的行业特点不同, 仅用 单一指标会造成所计算出的结果难免有失客观, 因此, 本研究分别取了产业中的产值、企业 单位数和从业人数三个指标, 并分别计算出了工业行业 40 个大类的区位摘值, 据此对各行业 的发展情况进行分析, 力求全面、客观。通过计算三种区位商的值并与 1 进行比较, 可以很 好的从 40 个行业大类中篮选出具有产业集聚的行业。考虑到不同行业在要素禀赋和产业特 点上的差异, 在选取过程中只要有一项区位商大于 1 都认为是符合要求的行业, 经过一系列 的计算, 最终将符合要求的 21 个产业集群类别整理如表 2 所示。 
表 2 陕西省第二产业的集聚度

\begin{tabular}{|c|c|c|c|}
\hline 分组 & 产值 & 企业数 & 从业人数 \\
\hline 煤炭开采和洗选业 & 6.35 & 6.15 & 2.93 \\
\hline 石油和天然气开采业 & 8.98 & 3.36 & 10. 09 \\
\hline 黑色金属矿采选业 & 1.74 & 1.84 & 1.55 \\
\hline 有色金属矿采选业 & 4.08 & 3. 43 & 3. 17 \\
\hline 非金属矿采选业 & 1.42 & 1.69 & 1.36 \\
\hline 开采辅助活动 & 4.92 & 10.49 & 4. 32 \\
\hline 农副食品加工业 & 0.96 & 1.43 & 1.00 \\
\hline 食品制造业 & 1.26 & 1.83 & 1.35 \\
\hline 酒、饮料和精制茶制造业 & 1.74 & 2.59 & 1.65 \\
\hline 烟草制品业 & 1.18 & 1.53 & 2. 47 \\
\hline 石油加工、炼焦及核燃料加工业 & 1.95 & 3.51 & 3.93 \\
\hline 医药制造业 & 1.18 & 1.70 & 1. 18 \\
\hline 非金属矿物制品业 & 1.15 & 1.30 & 1.02 \\
\hline 有色金属冶炼和压延加工业 & 1.67 & 1.72 & 2.05 \\
\hline 专用设备制造业 & 0.96 & 1.09 & 1. 07 \\
\hline 汽车制造业 & 0.79 & 0.55 & 1.11 \\
\hline 铁路、船舶、航空航天和其他运输设备制造业 & 0.88 & 1.27 & 0.82 \\
\hline 金属制品、机械和设备修理业 & 0.13 & 1.23 & 0.34 \\
\hline 电力、热力生产和供应业 & 1.18 & 1.61 & 2.18 \\
\hline 燃气生产和供应业 & 1.64 & 2.35 & 2. 36 \\
\hline 水的生产和供应业 & 0.82 & 1.19 & 1.20 \\
\hline
\end{tabular}

从表 2 可以看出, 产业集聚程度高的主要集中在煤炭开采业, 石油天然气开采业, 石油 加工业和开采辅助类, 这些行业基本是高度资源依赖型的, 其区位熵值较高, 集聚水平明显 高于全国平均水平，原因是陕西的煤、石油、天然气等资源较为丰富，陕西省有大量的企业 致力于矿产资源的开发, 反映出陕西省是一个资源大省的现实。除此之外, 油气开采类同时 也是从业人数指标上表现最优的, 其区位商值为 10.09 , 说明目前陕西省内从事石油和天然气 工作的人员多规模大。装备制造业作为陕西省主导产业，区位熵指数也基本超过 1 ，即与全 国相比有一定的比较优势，但有很多行业仅仅是单项指标的区位熵超过 1, 可见陕西省制造 业整体发展水平较低，发展比较好的行业主要是资源依赖型的。

\section{3 第三产业集聚度分析}

依据 2005 年第一次全国经济普查中的分类方法，第三产业分为 15 个具体产业，涉及的 行业众多, 覆盖的领域广泛, 考虑到数据收集的完整性, 本文依据《中国统计年鉴》2016 年 版对第三产业的参数描述, 把第三产业分为交通运输、仓储和邮政业, 批发零售业, 住宿和 餐饮业，金融业，房地产业五个大类进行分析。

为了避免根据单一指标计算的区位熵在评价某行业的发展情况时所产生的片面性，本文 分别使用了第三产业中的产业增加值和从业人员数的指标, 分别计算出了相应行业的区位摘 值, 据此对各行业的发展情况进行相关分析, 力求分析具备全面性和客观性。 
表 3 陕西省与全国第三产业分行业指标值

(单位: 亿元，万人）

\begin{tabular}{|c|c|c|c|c|c|c|}
\hline \multirow{2}{*}{ 地区 } & \multicolumn{2}{|c|}{ 交通运输, 仓储邮政业 } & \multicolumn{2}{|c|}{ 批发零售业 } & \multicolumn{2}{|c|}{ 住宿餐饮业 } \\
\hline & 产业增加值 & 就业人数 & 产业增加值 & 就业人数 & 产业增加值 & 就业人数 \\
\hline 陕西省 & 713.15 & 28.3 & 1504.04 & 25.8 & 432.02 & 10.6 \\
\hline 全 国 & 30487.8 & 854.4 & 66186.7 & 883.3 & 12153.7 & 276.1 \\
\hline \multirow{2}{*}{ 地区 } & \multicolumn{2}{|c|}{ 金融业 } & \multicolumn{2}{|c|}{ 房地产业 } & & \\
\hline & 产业增加值 & 就业人数 & 产业增加值 & 就业人数 & & \\
\hline 陕西省 & 1082. 37 & 20.3 & 695.53 & 11.5 & & \\
\hline 全 国 & 57872.6 & 606.8 & 41701 & 417.3 & & \\
\hline
\end{tabular}

表 4 陕西省与全国第三产业总值

(单位: 亿元, 万人)

\begin{tabular}{|c|c|c|}
\hline \multirow{2}{*}{ 地区 } & \multicolumn{2}{|c|}{ 第三产业 } \\
\cline { 2 - 3 } & 产业增加值 & 就业人数 \\
\hline 陕西省 & 7342.1 & 653.9 \\
\hline 全 国 & 341126.26 & 32839 \\
\hline
\end{tabular}

根据表 3 和表 4 计算得出陕西省第三产业分行业的区位熵值如表 5 所示。

表 5 陕西省第三产业分行业集聚度

\begin{tabular}{|c|c|c|}
\hline 行业 & 产业增加值 & 就业人数 \\
\hline 交通运输, 仓储邮政业 & 1.09 & 1.66 \\
\hline 批发零售业 & 1.06 & 1.47 \\
\hline 住宿餐饮业 & 1.65 & 1.93 \\
\hline 金融业 & 0.87 & 1.68 \\
\hline 房地产业 & 0.78 & 1.38 \\
\hline
\end{tabular}

在以产业增加值计算的产业区位熵中，交通运输、仓储邮政业，批发零售业和住宿餐饮 业的区位熵值均超过 1, 说明这些行业在全国同类行业中具有比较优势, 但金融业和房地产 业的发展强度与全国平均水平相比较缺乏发展优势, 还有一定的差距。按从业人数计算的区 位熵中，所有产业的区位熵值均大于 1 , 可见从人员的投入角度而言，陕西省第三产业的劳 动力有较强的优势, 其发展强度高于全国平均水平。

\section{4. 对策与建议}

产业的集聚度能够反映出地区经济的发展情况, 集聚度越高的产业对 GDP 的贡献越大, 通过对陕西省的三次产业进行集聚度的测算可以看出: 陕西省的第二、三产业具有相对优势, 第一产业总体处于劣势, 其中农业略好于其他产业, 第二产业中的煤炭开采和石油天然气开 采业都属于比较优势明显的行业, 装备制造业的集聚水平也好于平均水平, 第三产业中的交 通运输、仓储邮政业、批发零售业和住宿餐饮业整体集聚度都大于 1 , 具有一定的发展优势。

陕西已经形成了不同类型的产业集聚区，根据以上的分析，陕西在今后的产业发展中要 从以下几方面入手：第一，陕西省各区县要根据地区特色完善农业产业链，开拓农业产品深 加工业务, 实现完整周边服务产业链条式发展, 产业链上下游各环节形成地区品牌效应, 通 过集群内部的分工协调和产业链的拓展延伸来实现规模效应, 扩大招商引资增加资本投入, 更好实现农业产业集聚，增加地区生产总值，增加农民收入。第二，加速资源类产业集聚区的 
高端化发展。按照绿色、循环、低碳的理念，在稳步提供煤油气三大资源的同时，努力发展 清洁能源, 注重生态保护, 实现能源资源的永续利用, 促进陕西经济持续稳定健康发展。第 三, 不断改造提升传统的装备制造产业集群, 随着越来越多的新兴产业和现代服务产业的出 现，传统的装备制造业要适时而动，抓住新时期的新机遇，采用新型加工技术，增加产业集 聚经济效益, 获得新的发展。第四, 推动新一代信息技术产业集群的跨越式发展。以西安国 家高新开发区、西安经济开发区、西安咸阳新区和航空航天基地等为重要载体, 积极发展通 信设备制造、智能终端、关键零部件等通信产业集群, 延伸发展行业应用软件、嵌入式软件、 软件服务外包等高端软件产业集群。第五，依托西安经济开发区、西安国家高新技术产业区、 浐灞生态区等开发区，大力发展金融、物流、旅游、文化等优势现代服务业，加快现代服务 业产业园区建设, 以龙头企业为核心，吸引相关中小型企业进入，加快形成现代服务产业集 聚区。陕西正处在追赶超越阶段, 借助国家实施 “一带一路”、创新驱动和优先推进西部大 开发战略的历史机遇，大力促进陕西经济的持续健康发展。

\section{致谢}

本文为陕西科学技术研究发展研究计划项目 (项目编号: 2014KRM13)的阶段性成果之一。

\section{References}

[1] Marshall, A. Principles of Economics [M] .London: Macmillan, 1920

[2] Krugman, P. Increasing Returns and Economic Geography [J]. Journal of Political Economy, 1991, 99 ( 3) :483 499

[3] Alfred Weber. Industrial Location Theory[M],BeiJing: Commercial Press.1997

[4] Storper M. a. Walker, R. The Capitalist Imperative. Territory, Technology, and Industrial Growth[J]. Blackwell Publishers, Cambridge (USA) Oxford (UK), 1989(6): 154 - 182.

[5] Wang Zilong ,Tan Oingmei,XuXiaodi. The Empirical Analysis of Agglomeration Level Measurement of Industrial Cluster[J]. China Soft Science. 2006, (3):109-116

[6] Wang Jici. Some Related Concepts in China's Research of Industrial Cluster[J]. Acta Geographica Sinica.2004.(10):47-52

[7] Wu Xuehua ,Yang Huixin. Empirical Studies of Agglomeration of Manufacturing Industry in China[J] China's industrial economy。2004 (10)

[8] Liu Xiuyan. He Yumei. Agglomeration Economics Factor Endowment and Spatial Distribution of Industry: Evidence from China's Manufacturing Sector [J]. Industrial Economics Research . 2011(3): $10-19$.

[9] TangJie. Urban Industry Economic Analysis: An Economic Case Study [M]. Beijing :Beijing Institute of Economics Press.1989

[10]Portor Michael E. Competitive Strategy [M]. New York: The Free Press, 1999.

[11]Edward J Feser. Introduction to regional industry cluster regional industry cluster analysis[R]. Department of City \& Regional Planning, Chapel Hill University of North Carolina. 2001.

[12] Otsuka K, Sonobe T. A Cluster-Based Industrial Development Policy for Low-Income Countries[J]. Social Science Electronic Publishing, 2011.11. [61] 